\title{
Reduction of Furanoheliangolides
}

\section{Daiane C. Sass (PG) ${ }^{a^{*}}$; Vladimir C. G. Heleno (PQ) ${ }^{\mathrm{b}}$; Jader S. Barbosa (PG) $)^{\mathrm{a}}$; Gustavo O. Morais (PG) ${ }^{b}$; Fernando B. Da Costa (PQ) ${ }^{c}$; Mauricio G. Constantino (PQ). ${ }^{a}$}

${ }^{a}$ Departamento de Química, FFCLRP-USP; ${ }^{b}$ Núcleo de Pesquisas em Ciências Exatas e Tecnológicas,

UNIFRAN; ' Departamento de Ciências Farmacêuticas, FCFRP-USP.

*Tel: +55 (16)-36023879 daiane-sass@pg.ffclrp.usp.br

Keywords: Furanoheliangolides, Eremantholides and Stryker's Reagent.

\section{INTRODUCTION}

Furanoheliangolides and eremantholides (figure 1) are natural sesquiterpene lactones that show a number of interesting biological activities, e.g. trypanocidal, anti-inflammatory, anti-tumor, etc.

Figure 1. Sesquiterpene Lactones
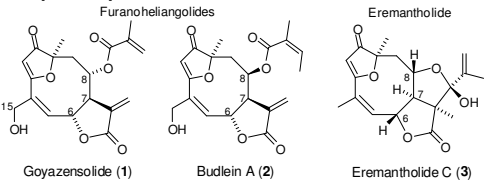

We have recently described a method for transforming furanoheliangolides (found in larger amounts in plants) into eremantholides using Stryker's reagent. ${ }^{1,2}$

In this work we explore an interesting aspect regarding the stereochemistry of these compounds. There are no eremantholides, in nature, with relative stereochemistry cis between the substituent's of positions $\mathrm{C}_{7}$ and $\mathrm{C}_{8}$. We have then decided to investigate if eremantholides could be prepared from cis substituted at $\mathrm{C}_{7}-\mathrm{C}_{8}$ furanoheliangolides such as budlein $A(2)$.

\section{RESULTS AND DISCUSSION}

We have found that many furanoheliangolide (including 1 and derivatives $\mathbf{4}, 5$ and 6) can be reduced with Stryker's reagent in a reasonably selective way: despite the large number and variety of reducible functions present on these molecules, the addition of hydride to the a-methylene-lactone system followed by cyclization, as shown in scheme 1 , was consistently a preferable path.

Scheme 1.

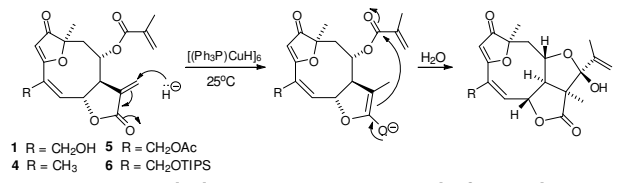

Substrates containing oxygenated functions at $\mathrm{C}_{15}$ (such as 1, 5 and 6) gave also some products of reduction of the $\alpha, \beta, \gamma, \delta$-unsaturated furanone, but eremantholides were always obtained with yields between 30 to $50 \%$ in all cases of scheme 1 .

However, when we treated budlein A (2) with Stryker's reagent under the same conditions, no eremantholide was formed at all. As shown is scheme 2, only reduced products were formed, and no cyclization occurred.

Scheme 2.

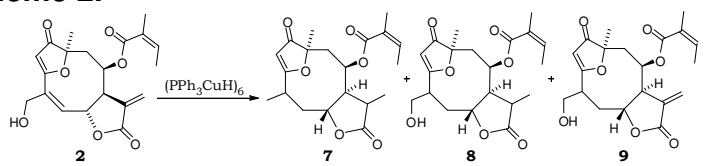

By using molecular models or molecular mechanics computer programs we can see that, due to a peculiar conformation of the 9-membered ring, the vicinity relationship of the groups attached to carbons $\mathrm{C}_{7}$ and $\mathrm{C}_{8}$ is opposite to what we usually expect from examination of planar structural formulas: the trans disposed groups (as in cases of scheme 1) are nearer to each other than the cis disposed groups (as in case of scheme 2).

In figure 2 are depicted the more stable conformations of the molecules of goiazensolide (1) and of budlein A (2).

Figure 2. Conformations of the molecules 1 and 2
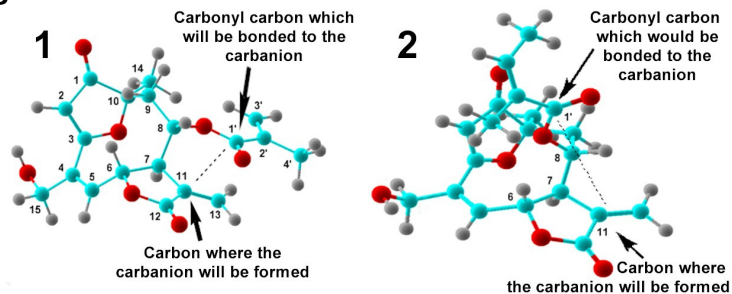

In this picture we can see that the carbon atoms that should be connected to form eremantholides are at a favourable distance for (1), but are very far apart from each others in structure 2.

\section{CONCLUSION}

We can conclude that only trans-substituted at $\mathrm{C}_{7}$ and $\mathrm{C}_{8}$ furanoheliangolide can give eremantholides, because the cis configuration determines a conformation where the groups that connect to each others are maintained far apart.

\section{ACKNOWLEDGEMENTS}

FAPESP, CAPES and CNPQ.

\section{REFERENCES}

${ }^{1}$ Sass, D.C. et al. Tetrahedron Lett. 2008, 49, 3877-3880.

${ }^{2}$ Sass, D.C. et al. $13^{a}$ BMOS 2009. 